\title{
REFLECTIVE ONTOLOGY AND INTUITIVE CREDibility IN CHINESE SiX LiNES PREDICTION
}

\section{William Matthews}

\begin{abstract}
Any form of divination can be intuitively compelling without the need for ontological elaboration, but practices like Chinese six lines prediction involve complex ontological accounts, raising the question of what effect this has on divination's authority and persuasiveness. The explicit ontology of six lines prediction appears to make it especially persuasive, because it provides a coherent model of epistemology and causation that is readily comparable to scientific observation and description based on constant principles. Meanwhile, six lines prediction's mathematical character adds to its intuitive authority. By relying on a predetermined system of correlates, it creates the impression that the diviner is not the source of the divinatory result or its interpretation. This likely allows six lines prediction to flourish in an environment in which it is officially classified as 'superstition'.
\end{abstract}

Keywords: calculatory divination, China, cognition, divination, ontology, persuasion, Yijing

Master Tao practiced six lines prediction outside on a pedestrian street in a newly renovated area of Hangzhou, a city in eastern China. This divination method yields highly specific verdicts based on constant cosmic principles that are identified and interpreted by the diviner according to fixed principles of correlation with specific phenomena-a prime example of calculatory divination, involving no conception of the cosmos as agentive, in the sense used in this issue. The principles of six lines prediction are justified according to an explicit ontology - a fully established account of the fundamental kinds of things that exist-which diviners draw on to explain how their practice works. 
The six lines method is based on the two-millennia-old Yijing (I Ching or Book of Changes), a divination manual and cosmological text that includes 64 hexagrams (gua), diagrams of six broken or unbroken lines, themselves composed of the possible combinations of eight trigrams (also gua) of three lines each. ${ }^{1}$ Each of these is considered to index a possible state of the cosmos, from the perspective of the inquirer, and is accompanied by highly abstract descriptions. These are followed by a series of commentaries that describe the origins of the trigrams in sage observations about natural patterns and correlate them with specific kinds of phenomena, including colors, directions, and animals. Six lines prediction functions by deriving one of the Yijing's hexagrams mechanically, typically by throwing coins, without reference to the text itself. Diviners understand the fall of coins to reflect the configuration of $q i$ (the matter-energy that constitutes the whole cosmos) at a particular spatio-temporal point focused on the client. Qi is understood as operating according to a constant principle of transformation through Five Phases (wuxing) of metal, wood, water, fire, and earth. The lines of the hexagram indicate relationships between these phases of $q i$ and their effects on different kinds of relationships (Matthews 2022, forthcoming a).

Together with his six lines equipment, Master Tao also possessed a pot of bamboo strips used for stick divination (chouqian), which was placed on the ground in front of him. In this form of divination, the client picks up the wooden pot of sticks, the ends of which are numbered, and shakes it more or less horizontally until one of the sticks protrudes and falls out. The number marked on that stick is then looked up in a book, where it is matched to a line of verse describing the divinatory outcome. In this case, the verse is handwritten or pasted into Master Tao's notebook and divorced of any connection to a local temple, which might otherwise prompt reflection on a supposed underlying agentive ontology in which these verses are explained as statements from gods. The diviner does little more than offer the sticks and notes, and in temples this form of divination is typically carried out directly by the client.

During my time in Hangzhou, I only ever observed three clients do this. One, a relatively elderly woman, requested to use the sticks, repeatedly consulting them for about a half-hour and clocking up a bill of around $170 \mathrm{RMB}$ (around $£ 17$ at the then exchange rate, equivalent to almost four six lines consultations). Meanwhile, Master Tao continued to carry out six lines predictions for other clients, occasionally shooting disdainful glances in her direction. He was clearly skeptical of her determined pursuit of a positive outcome and was frank with me about his thoughts on the technique itself. Stick divination, in his view, while a "substitute" for six lines, was "thoroughly inaccurate, lacking any sound basis, and merely a means of seeking psychological consolation" (meiyou shenme zhunque, meiyou shenme daoli, zhi qiu xinli de yi ge anwei). As an expert practitioner, Master Tao obviously had an interest in promoting 
six lines prediction, yet he still offered stick divination despite his attitude toward it, having been given the equipment by a local association (while he considered six lines superior to other forms of divination, he was not as critical of all of them). Although rarely used, the pot of sticks served as a recognizable indicator of divinatory services to passers-by. In contrast to this relatively simple form of divination, six lines prediction is based on an extremely complex, explicit ontology and requires an expert to interpret divinatory outcomes. This was Master Tao's primary business and the main reason why he had so many returning clients.

Is there something about its explicit ontology, in the sense discussed above and in the introduction, that makes six lines prediction relatively more persuasive than other forms such as stick divination, which lack such an explanation? The practice draws on an ontological categorization of time and space according to the Five Phases of $q i$, concepts that are known to most clients and others in Chinese society, even though their understanding is typically less detailed than that of diviners. This is a calculatory ontology, in which divination is explained based on constant cosmic principles, but other forms found in China (more often in rural areas) involve agentive conceptions, asking questions of gods and spirits via mechanical means such as dropping wooden blocks or via possession. It is thus worth considering both what the presence of an explicit ontology might do for divinatory persuasion and how it might vary depending on the precise content of that ontology.

Following what Michael Scott (2007) and Martin Holbraad and Morten Axel Pedersen (2017) describe as 'deep ontology', we might identify the explicit ontology of six lines prediction as indexing a particular underlying way of apprehending the world-the idea being that patterns of belief and practice across domains from kinship to cosmology indicate fundamental, culture-bound mental mechanisms for perception and action. ' 'Deep ontology' approaches presume a coherent underlying logic in various domains of cultural practice (Scott 2007) or even posit cognitive schemata that systematically integrate all experience into a basic ontological framework (Descola 2013). This article offers a different perspective, informed by what is known about different forms of human cognition. In this view, the idea of 'deep ontology', as opposed to explicit accounts of kinds of beings, is profoundly unrealistic. It is impossible via ethnography to identify the underlying cognitive mechanisms that would make 'deep ontology' credible. Experimental evidence from cognitive and developmental psychology indicates that human cognition involves the interaction of context-specific processes rather than a single, coherent mechanism of perception and understanding, operating on intuitive and reflective levels that imply quite distinct, even contradictory, judgments (Boyer 2010; Matthews 2022).

The explanatory power of ontology is therefore limited. It is better seen instead in the form of an explicit account of what exists, as a cultural product 
to be explained in terms of other mechanisms. As I have argued elsewhere (Matthews 2022), these can be considered 'systematic' ontologies; people also make reflective ontological assumptions (active considerations of what something is, in the absence of a comprehensive account of what exists). 'Deep' or implicit ontologies-as comprehensive frameworks underlying people's beliefs and their concomitant behavior-exist only as fictions of anthropological analysis. Throughout the rest of the article I therefore use the term 'ontology' to mean a systematic, explicit account.

As David Zeitlyn argues (this issue), ontology is a matter of individual perspective rather than the property of a practice, including practices that involve reference to ontological accounts. This is especially relevant for divination. While the Chinese, Greek, and Nuosu examples discussed in this issue all draw on rich accounts of the categories of being invoked in divination, many forms do not, including the paradigmatic case of Azande oracles (Evans-Pritchard [1937] 1976) and Mambila spider divination (Zeitlyn 1987, 1990, 1993, this issue). Rather, the methods simply 'work', and that's that. ${ }^{4}$ In comparative perspective, therefore, the relevant question concerns the conditions which promote divination practices that $d o$ invoke explicit ontology (i.e., to explain the existence of ontological accounts in relation to some divination systems), and the effects that invoking ontology has on divinatory procedure, authority, and persuasiveness.

Addressing the specific question of the persuasive role of ontology in six lines prediction, the ethnography discussed in this article serves to illustrate a broader explanatory framework. To begin, this requires establishing the role of intuitive and reflective cognition in divination, particularly in terms of how this makes divination appear authoritative via 'ostensive detachment' (Boyer 2020). Once the role of intuitive and reflective cognition is established, we can examine how it is affected by the interpretive system of six lines prediction, and how this in turn is influenced by its explicit ontological assumptions. The role of ontology is then explored in terms of the persuasiveness of the practice, particularly in the context of competition with alternative sources of knowledge. This is considered in relation to questions of political legitimacy, in terms of both the historical origins of six lines prediction under the Han Empire and today's environment in which 'science' (kexue) is endorsed by the state and 'superstition' (mixin) condemned. Causally speaking on the level of transmission and understanding between individuals, ontology pertains to persuasiveness as a form of secondary, reflective elaboration on the intuitive authority possessed by any divination practice. Therefore, a distinction is drawn between intuitive authority and reflective persuasiveness in the discussion below. Finally, the conclusion offers a series of hypotheses following on from the account of ontology and persuasiveness, which would allow the explanatory framework to be tested in this and other ethnographic contexts. 


\section{Intuitive and Reflective Cognition in Divination}

Anthropologists of divination have long noted that the practice involves the interplay of two distinct forms of cognition that have often been assigned different labels by scholars: 'synchronous' versus 'sequential' (Parkin 1991), 'representative' versus 'conjectural' (Swancutt 2006), or 'presentational' and 'representational' (Tedlock 2001). Here, I refer to them as 'intuition' and 'reflection', ${ }^{5}$ not to add to the proliferation of terms but to align them with the wider body of literature known as 'dual process theory' and its application in anthropology (Baumard and Boyer 2013; Boyer 1998; Sperber 1997). The interplay of intuition and reflection is not limited to divination-it is a ubiquitous feature of human thought, but one that divination techniques make especially obvious (Matthews, forthcoming b).

Put simply, 'intuition' (also referred to as 'type 1' processing) refers to fast, automatic, low-effort judgments and decisions and the concepts on which they rely. In contrast, 'reflection' ('type 2' processing) refers to slow, deliberative, high-effort judgments and decisions, and concepts that must be explicitly represented. For example, one's gut reaction to a moral transgression would be intuitive, whereas justifying that reaction in terms of explicit moral values or principles would be reflective (Haidt 2001). Intuitive concepts are those mobilized in intuitive judgments or in the formation or invocation of intuitive beliefs-from implicit concepts such as 'agent' or 'solid' to learned concepts such as types of animal-while reflective concepts are those that cannot become intuitive in spite of familiarity and must always be effortfully, consciously represented, such as prime factors or chemical formulae (Sperber 1997). Notably, intuition involves pattern recognition through learned associations and conceptual cues, as opposed to high-effort rules-based reflection; the process by which intuitive judgments are reached is not consciously accessible (Smith and Collins 2009: 201). While intuition and reflection thus describe distinct shared features of different forms of cognition, this does not mean that all intuitive or reflective processes are of a single type. Intuitive processing in particular encompasses a wide range of different cognitive mechanisms that can operate in parallel (Evans 2009).

All acts of divination necessarily involve both intuitive and reflective processes. Intuition in divination typically involves spontaneous associations on the part of the diviner or client that are then reflectively linked to life events, such as the identification of salient life circumstances in the polyvalent divinatory stories used by Ifá diviners (Holbraad 2012) or the synchronicity identified by Jung (1989) in the Yijing (an approach quite unlike that of six lines prediction). The reflective processes typically remarked on by anthropologists of divination involve the systematic ordering of divinatory results or the ratiocination involved in drawing conclusions from results of mechanical divination 
techniques, which necessarily contain the potential for procedural error and thus have 'correct' or 'incorrect' interpretations (Zeitlyn 1990). From the perspective of dual process theory, emphasizing intuitive or reflective judgments is itself a reflective act. Likewise, a skilled diviner of a system like six lines prediction, which removes any formal interpretive role for intuitive associations, will nonetheless rely on intuitive processes such as the automatic recall of divinatory procedure or the referents of certain outcomes. As such, it is not accurate to characterize different techniques as more or less intuitive or reflective; rather, what is crucial is the degree to which certain kinds of intuitive or reflective processes are reflectively emphasized (Matthews, forthcoming b).

Building on a broadly dual process model, Pascal Boyer (2020) convincingly argues that the cross-cultural recurrence of divination is best explained in terms of intuitions designed to make individuals alert to potential deception in speech. This draws particularly on the importance of 'epistemic vigilance', the role of cognitive mechanisms sensitive to social cues of possible accidental or deliberate misinformation in communication (Sperber et al. 2010). The prevalence of divination, Boyer argues, stems from the ostensive detachment of divinatory verdicts. That is, verdicts as communicative acts are presented as originating from the mechanism of divination itself rather than from the diviner. In mechanical forms, this is demonstrably due to the apparent inability of the diviner to influence the outcome (fall of coins, shape of entrails, movement of spider), and in inspired forms such as possession, it is due to the adoption of a distinctive voice or manner of speech. This removes intuitive obstacles to doubting a divinatory verdict, notably the (potentially malign) intention of a human speaker; it does not provide positive reasons for believing in a divinatory verdict.

Under the correct conditions, ostensive detachment makes any divination technique intuitively authoritative. The most relevant of Boyer's conditions for the present argument is that the underlying facts of concern to the inquirer are not readily knowable via other means. Divination is not typically used if apparently more reliable means of deriving the required information exist. As Boyer acknowledges, ostensive detachment predicts adherence to divination as a source of authoritative knowledge; it does not dictate whether or not people are actually persuaded reflectively that divinatory verdicts, or the systems on which they are based, are empirically valid. ${ }^{6}$ Indeed, as Boyer (2020: 121) suggests, this may well be a reason why divination in certain contexts is linked to wider, socially accepted cosmologies involving supernatural agents believed to be in possession of certain forms of knowledge. It follows from this that, as I argue in the rest of the article, while ontological elaboration is not necessary for divination to be authoritative, it might well help it remain convincing under social conditions in which it competes with other authoritative sources of information. 


\section{Interpretation in Six Lines Prediction and the Impact of Ostensive Detachment}

Divination systems can be categorized according to the degree of emphasis they place on intuitive or reflective judgments during the interpretation of a verdict, although they all rely on 'stocks of images' (Feuchtwang, this issue) to derive meaning. Matthews (forthcoming b) characterizes 'generative' interpretation as being based on polyvalent verdicts that provoke intuitive associations on the part of the diviner or client, thus creating meaningful connections to the subject of inquiry, and sees 'reductive' interpretation as actively suppressing the role of intuitive associations in linking divinatory outcomes to client circumstances. ${ }^{7}$ Stick divination is generative, yielding polyvalent verdicts in the form of poetic verse composed in terse classical Chinese of a form unfamiliar to most people today. Because these verses are highly abstract, they function not by providing specific answers but by provoking spontaneous associations of meaning for the client, who is then able to interpret the same result (i.e., the specific verse derived) to reach a range of possible verdicts (i.e., the diagnosis of what is actually going on). ${ }^{8}$

In contrast, six lines prediction is reductive, relying on predetermined, formalized sets of correlates operating via fixed principles to exclude the possibility of spontaneous association. As described above, the fall of coins in six lines prediction yields a hexagram. Based on an established classification of the 64 hexagrams, each line corresponds to one of the Five Phases of $q i$, and based on the lines' positions in relation to one another, they have additional correlates determined by established cosmological theories. Typically, clients are instructed not to mention their inquiry until the salient correlates of the hexagram have been identified by the diviner-that is, the question of concern should not be raised until after the divinatory result has been generated (except on rare occasions when clients unfamiliar with the system do not wait for instructions). The correlates are fixed for each hexagram and also take into account the point in the sexagenary cycle of the calendar at which the hexagram was derived-a sequence determined by combining the astrologically derived ten Heavenly Stems and twelve Earthly Branches. The specific relationship between the phase of $q i$ promoted by this, and that associated with each line of the hexagram, determines the quality of the personal relationships which correspond to that line. So the method is highly technical, and the correlates have fixed referents; rather than constituting polyvalent symbols, they function as a specifically defined index of the cosmic situation. There is no room for the diviner to create new meanings by recombining correlates, for example, or to suggest that certain correlates could be substituted for others. What this means is that each set of correlates taken into account reduces the space for interpretation (Matthews, forthcoming a). However, it should be 
noted that members of the category that indexes the kind of relationship of certain phenomena to the client can have a variety of referents, all of which are connected by the quality of the relationship. This means that, following annotation of the hexagram, if clients do explain their problems, they can be interpreted accordingly but still following the fixed correlative system.

This mode of interpretation has an effect on the nature of divinatory verdicts. In six lines prediction, verdicts are typically highly specific, detailing optimum times, places, and directions that can help determine actions. This in itself is not particularly unusual among divination systems (although it does mark six lines out from stick divination). What is distinctive is that these specificities follow directly, and inevitably, from the hexagram cast as a function of the correlative system, without the need for the diviner or client to draw spontaneous connections (thus, the system itself is infallible, even if the diviner may make mistakes). This is because six lines prediction, like its cognate disciplines of fengshui and bazi fate-calculation, produces answers only in terms of the correlative system. The divinatory result is a detailed index of general cosmic conditions rather than a specific answer, and the task of interpretation is to narrow this down to answer the client's specific inquiry (Matthews, forthcoming b). Based on the correlates of the hexagram, the interactional effects of phases of $q i$ revealed by the hexagram are themselves correlated with the temporal cycle of $q i$ to determine more or less auspicious dates and times, with the spatial correlates of $q i$ to identify more or less auspicious places and directions, and the qi configurations associated with individuals based on their birth and relationship to the client. This lends the procedure an apparently mathematical character ${ }^{9}$ and produces what is essentially a projection of propensity for good fortune into the present and future that can be used as a guide for action. Indeed, many divination inquiries involve seeking optimum times and places for action, typically phrased in terms of when one should do something (such as move house, make a hospital appointment, and so on), and seeking the best point from a range of options. Even when questions are more direct-such as whether a prospective spouse is a good match, or whether a specific goal (such as a business deal) can be achieved-they are still arrived at through finding the optimum configuration of correlates. ${ }^{10}$

The features so far described-mechanical procedure, fixed correlates, mathematical character, reductive interpretation, and the fact that questions are posed after the hexagram has been generated and annotated-help six lines prediction appear especially ostensibly detached. As already described, the mechanical procedure of throwing coins serves to demonstrate that the diviner is not the author of the divinatory result. The impact of ostensive detachment is increased if divinatory interpretation is already known by the client to rely on predetermined sets of meanings and strict rules, as this further reduces the potential for the diviner to be perceived as having influenced the verdict; this 
amounts to a reflective awareness of the diviner's detachment on the part of a client, but in no way requires the entertainment of ontological assumptions. It is plausible that regular clients' repeat exposure to the method, combined with this knowledge, may strengthen intuitive perception of ostensive detachment as well, and this in turn would suggest that divination could become more intuitively authoritative as a result of repeated exposure.

However, regardless of a client's awareness of the limits imposed by the correlative system, the way in which Master Tao would establish the correlates of the coins-annotating them in a table-like arrangement, counting out sequences on his knuckles, and referring to visibly placed tables of hexagram correlates-lends the procedure the appearance of working out a mathematical puzzle. These cues to six lines prediction's apparently mathematical character suggest greater intuitive authority. Not only is the ostensibly detached source of the verdict present in the form of the coins, but it is cross-referenced with other ostensibly detached sources that the diviner does not manipulate during interpretation, and the diviner's determining of the correlates readily appears to follow a fixed sequence. If clients are familiar with the system, then their awareness of the reductive suppression of the role of intuitive associations makes them reflectively aware that the diviner is unlikely to bring in judgments or considerations extrinsic to the divinatory system. Finally, in addition to the above, the most important correlates of the specific hexagram, and the salient relationships between them, are identified by the diviner before the client poses their question, so they cannot appear to have been influenced by it. Taken together, these features mean not only that the procedure producing the result is ostensibly detached, but also that the effect of this ostensive detachment is extended via a client's intuitive and reflective responses to the interpretive procedure that follows.

The correlative system draws on a particular explicit ontology, as discussed in the next section, but this does not in itself play a role in six lines prediction's ostensive detachment. That is, an awareness of the explicit ontology of the correlates is irrelevant, because ostensive detachment is the result of intuitive contextual cues about the reliability of statements rather than about explicitly represented principles. Indeed, while some of these qualities of six lines prediction are likely to be enhanced by familiarity with the system on the part of the client-particularly the predetermined correlates and their relationships-if this familiarity enhances ostensive detachment, it is because it provides a further contextual cue that the divinatory result and verdict stem from the procedure and correlative system rather than from the diviner. It is not because familiarity requires a reflective understanding of the underlying ontology. It is reasonable to assume that most clients are familiar with the system, via repeat consultations, awareness of cognate methods such as bazi and fengshui, the use of the lunar calendar and Chinese medicine, and the socio-cultural salience 
of these and related ideas. Moreover, many clients take an active interest in the logic of the correlative system in addition to its relevance to their own inquiry during a consultation. Lack of familiarity may mean that six lines prediction's ostensive detachment is lower for a wholly naive client, but it is still likely to be high because the mathematical character of immediate interpretation, stemming from the coin fall, is readily apparent from the diviner's rapid annotation of the hexagram prior to being asked a specific question.

Stick divination, as described above, is ostensibly detached only insofar as the result is generated by the random emergence of one stick from the pot and the fact that each stick corresponds with a predetermined verse. Shaking the pot is arguably more intuitively open to interference than throwing the coins, as it can be influenced directly by the person holding it. Moreover, the epistemic value of divination is relative, depending on the presence or absence of alternative sources of information (Boyer 2020). Being presented alongside highly detached six lines prediction, by a diviner advertising himself and having a reputation as a skilled professional in that system, and divorced from its usual context of popular religious authority in a temple, stick divination is affected by perceptual cues that make it considerably less intuitively compelling.

The features of six lines prediction described so far are sufficient to make it especially intuitively compelling and do not rely on the client representing it in ontological terms. It bears emphasizing that the correlative system is important for establishing this intuitive authority because it extends ostensive detachment, not because it introduces a set of credible cosmological theories or ontological justifications for divination as an epistemology. This remains the case even though these effects of the correlative system do stem from cosmological expertise on the part of the diviner. One need not 'believe in' correlative cosmology or even explicitly reflect on it for its reductive logic to be intuitively compelling - in fact, one can actively disbelieve it. But as Boyer (2020) notes, the intuitive authority of divinatory verdicts is not the same as their persuasiveness. This is the subject of the next section, which argues that explicit ontology lends persuasiveness to six lines prediction.

\section{Ontology and Persuasion}

Historically, six lines prediction developed from a range of earlier practices during the Han dynasty, tracing its formal origins to the method of 'attached stem divination' (najia shifa) developed by the scholar Jing Fang the Younger in the first century BCE (Hulsewé 1986). Jing Fang's system involved making the Yijing-canonized in 136 BCE as one of the 'Five Classics' (wujing) underpinning Han state ideology, that is, the ideology of the court and bureaucracycompatible with the correlative system of stems and branches (hence the name) 
and the Five Phases based on universal $q i$ that had developed from technical mantic practices over the previous centuries. In this way, six lines prediction has its origins in the adaptation of existing divination techniques such that they cohered with the explicit principles of correlative cosmology; it is a divination technique tailored to cosmological purposes, and therefore directly concerned with ontological questions and their epistemological implications. The idea of phases had been used by the Han dynasty and the preceding Qin dynasty to justify their rule over China. The dynasties were linked with phases following a sequence, presenting dynastic succession as part of the cosmological order. By this point, Yijing-based divination "had undergone a change in purpose" (Loewe 2005: 75) from producing yes/no answers to yielding detailed indices of cosmic conditions and thus the potential for auspicious action (ibid.: 75-76). The development of six lines prediction was hence closely bound to the establishment of qi-based correlative cosmology and the authority of the Yijing as crucial sources of cosmological legitimacy for the imperial state. Based on this, it is reasonable to argue that in the context of the Han and subsequent empires, a shared underlying set of ontological assumptions with imperial cosmology would have given six lines prediction and its antecedent methods significant persuasive power.

This is particularly so if we accept Boyer's (2020) core argument that divination practices are likely to flourish in the absence of alternative sources of information about the world. It is a reasonable hypothesis (and assessable in relation to the historical record) that in the context of a hegemonic political cosmology-which through its reliance on a correlative system and the authority of ancient texts ${ }^{11}$ itself appears ostensibly detached-a divination system that shares those features will derive greater legitimacy and thus not only be intuitively authoritative but reflectively persuasive. That is, beyond removing intuitive obstacles to doubt, the ontology of six lines prediction offers positive reasons for individuals to engage with it. These reasons are reflective, cognitively speaking, as they involve conscious mental representations of the world as described by six lines prediction and deliberative judgments about the relationship between these ideas, the epistemology of and techniques employed in six lines prediction, and competing accounts or sources of information, such as science.

But why might its explicit ontology make six lines prediction persuasive today, in the context of an industrialized modern state that actively promotes science and condemns superstition, including divination (Li 2019; Matthews 2017a) $?^{12}$ Before considering this, it is worth reviewing some of the core ontological assumptions of six lines prediction and how these relate to explicit epistemology, bearing in mind the definition of ontology as a set of explicit ideas provided above. This is essential, as reflective cognition involves the conscious representation of explicit concepts and their deliberate evaluation. From the 
perspective of a diviner like Master Tao, or a client sufficiently familiar with six lines prediction, the following explicit ontological claims are central:

- The cosmos (or reality) is composed entirely of $q i$, which is both matter and energy. Everything, including thoughts and emotions, is therefore describable in terms of $q i$.

- Reality has a single origin of undifferentiated qi.

- Qi constantly transforms according to constant laws, as described by the sequence of the Five Phases and the Heavenly Stems and Earthly Branches.

- These principles apply to both time and space.

Considering the assumptions this makes about physicality (the substantive body) and interiority (subjective selfhood) and the continuity or discontinuity between them (Descola 2013), the ontology that explicitly justifies six lines prediction, which is shared with other practices and derives from the correlative cosmology of the early Chinese empires, can be described as monist, with presumed continuity between physicality and interiority within and across beings (bearing in mind that this account, as an ontological account, has no bearing on the intuitive authority of six lines prediction). This ontology is closely tied to six lines prediction's epistemological focus on identifying resemblances between phenomena as indicative of underlying common configurations of qi (e.g., two instances of the same hexagram indicate two instances of a common qi configuration). This approach is likewise not limited to six lines prediction but is shared with cognate knowledge practices rooted in correlative cosmology.

The explicit ontological principles of correlative cosmology as put into practice by diviners are homological (Matthews 2017b), with similar traits deriving from a common origin, as opposed to analogical (Descola 2013), in which resemblances indicate observed convergence from distinct origins (see also Almqvist, this issue). Indeed, such questions of the ontological and epistemological status of similarity and difference are central to the theory and methods of six lines prediction and cognate practices. The Yijing itself describes how the eight trigrams, which combine to make the hexagrams, were derived by the sage Bao Xi (as translated by Lynn 1994: 77) through abstracting from the observation of natural patterns and resemblances:

When in ancient times Lord Bao Xi ruled the world as sovereign, he looked upward and observed the images in heaven and looked downward and observed the models that the earth provided. He observed the patterns on birds and beasts and what things were suitable for the land ... Nearby, adopting things from his own person, and afar, adopting them from other things, he thereupon made the eight trigrams in order to become thoroughly conversant with the virtues inherent in the numinous and the bright and to classify the myriad things in terms of their true, innate natures. 
Here, the trigrams are presented as deriving from natural patterns and are thus cast as a usable basis to understand natural phenomena. With an understanding of the trigrams as cosmic principles, later elaborated in terms of $q i$, the world can be understood and change predicted. This means that in theory coins (or any other dedicated mechanism) are not necessary to make diagnoses since any object, given sufficient contextual information, can yield information about any other object (the logic behind fengshui). The use of coins is considered more accurate, although some diviners using related forms of Yijing divination make causal diagnoses based on appearances. ${ }^{13}$ The fall of coins, in this view, is not random but determined by the local configuration of $q i$, the qi-field (qichang); that is, it is determined by the correlative system and so in principle can also be predicted by it. However, in practice the fallibility of the diviner is emphasized, as a human observer's capacity to account for different factors is limited.

Diviners like Master Tao, along with their students and clients, draw on these features to argue that six lines prediction, or Yijing divination more generally, is 'scientific'. In particular, they emphasize the role of observations of natural patterns in deriving the trigrams, and draw direct parallels between the cosmogony of the Yijing and the Big Bang (Matthews 2017a, 2017b). At the same time, the Yijing is widely considered 'profound' (shen'ao) by diviners and clients (Matthews 2017a: 179), embodying ancient wisdom that fits with scientific accounts in its own right. This should be understood in relation to a longer tradition of finding parallels between Chinese cosmologies, including Buddhism (Hammerstrom 2015), and science, traceable through the Republican era back to the nineteenth century and earlier (Elman 2005) and concerned at least in part with maintaining the legitimacy and authority of the former (Homola 2014; Lackner 2012).

However, diviners, students, and many clients are also interested in developing their own understandings of the cosmos, and the ontology of six lines prediction discussed above lends itself especially well to comparison with science through its focus on observation, emphasis on constant cosmic principles, unitary origin, and monism (Matthews 2017b). Indeed, while careful comparison of Yijing cosmology and physics relies on reflective deliberation, presenting a simplified analogy between the two can prompt a recognition of their ostensive commonalities for an individual who has some (but not too much) familiarity with both. Thus, the specific comparison can be reflectively persuasive despite the fact that six lines prediction and physics have very different techniques of observation, forms of epistemological scrutiny, and empirical content. Nonetheless, there are sufficient structural parallels to sustain the comparison and its persuasiveness if one has a sense of the broad epistemological and ontological orientations of both but lacks detailed knowledge of physics as a scientific practice (which is hardly widespread) or of the 
practicalities and intricacies of divination. In contrast, a practice such as stick divination as offered by Master Tao lacks the explicit ontological framework that provides the interpretive logic of six lines prediction and its origins in the Yijing, which facilitate such analogies. Therefore, in order to establish itself as 'scientific', comparable to local temple deities being explained in terms of electromagnetism (Chau 2006: 104-105), stick divination would need to appeal to ideas extrinsic to its own theoretical basis that lack the same intuitive similarity to its own logic.

In a socio-political context in which divination is subject to condemnation as superstition by both the state and many members of the public, this likely grants six lines prediction and cognate practices a significant persuasive advantage. Not only can diviners present a case for considering the practice 'scientific' as opposed to 'superstitious', but in doing so they can draw on the moral and epistemological prestige of, and popular trust placed in, science itself. Thus, in addition to its ostensive detachment, six lines prediction also draws on explicit reflective comparisons and presents a comprehensive account of the cosmos according to which any phenomenon can supposedly be explained, which can itself be the object of reflection.

Ontological elaboration presents six lines prediction not simply as intuitively authoritative, but as reflectively persuasive based on its systematic accounting for complexity in terms of a limited number of constant principles. That is, it provides a rationalized account of similarity and difference across scales that accommodates both repeating patterns of social life and the contingency of individual circumstances. As Charles Stafford (2009: 117-118) has argued for cognate systems, the correlative system generates so many possible combinations that the probability of exactly the same outcome occurring twice is extremely small, reinforcing the idea that the client's situation is unique in spite of its restriction of possibilities (cf. Homola, this issue). The homological account of correlative cosmology is able to zoom in or out on a specific phenomenon by accounting for more or fewer sets of correlates (e.g., phases of specific lines, their relationship with times and places, and so on). Thus, while in principle all phenomena are reducible to the flow of $q i$, their specificity is nonetheless preserved through particular combinations, something already present in the Ten Wings commentaries of the Yijing (Matthews 2018). Finally, all of this is presented (like science) in terms of amoral cosmic principles, a fact remarked on by Stephan Feuchtwang (1974: 223) and Maurice Freedman (1979: 211) in relation to the cognate practice of fengshui. Moral culpability is removed from diagnoses by explaining human action in terms of cosmic principles that naturally stem from the interaction of $q i$ fields. This allows for the possibility of rationalizing difficult situations via a system through which they can be entirely explained, thus adding further to the practice's persuasiveness. 


\section{Conclusions and Prospects for Future Comparative Research}

This article's core argument, informed by a dual process model of cognition, has been that explicit ontologies, when attached to divination methods, help to make divinatory verdicts (and systems) more persuasive. While all divination practices derive intuitive authority from ostensive detachment, not all of them are subject to ontological elaboration. Six lines prediction constitutes an example that derives persuasiveness from an explicit calculatory ontology, ${ }^{14}$ which in contemporary China facilitates comparisons with science that further increase its reflective persuasiveness. The ontology attached to six lines prediction also affects the way in which verdicts are derived via the interpretive method (even if it is not mentally represented), as diviners must engage in a series of annotations of the result according to a fixed framework of correlates, which provide a client with further cues to its ostensive detachment. This final section considers some of the comparative implications of the preceding argument, including several hypotheses that could be productive for further investigation.

Six lines prediction possesses a range of features that make it intuitively authoritative. Nonetheless, the key feature that extends ostensive detachment from divinatory procedure to interpretation, the correlative system, derives historically from efforts to make Yijing divination an explicitly cosmological practice. In this sense, while clients do not need to be aware of the ontology of six lines prediction for it to possess intuitive authority, its intuitive authority is enhanced by features of the interpretive process that are (or originally were) based on explicit ontological assumptions. Ontology does, however, make six lines prediction persuasive on a reflective level by justifying the practice according to authoritative textual descriptions of natural observations and a comprehensive explanatory framework for all phenomena based on those observations. In the context of six lines prediction's initial development in the Han dynasty, its acceptance was bolstered by the fact that it shared its cosmology with that of the imperial state, granting it moral and political authority. Today, while condemned as superstition, the same features, including the apparently mathematical character of the interpretive system, nevertheless allow six lines prediction to remain not only intuitively authoritative but also reflectively persuasive in an environment in which science provides the gold standard of objective and morally good knowledge. This allows diviners like Master Tao to present their practice as scientific in a way that is not possible for practices such as stick divination.

Considering the role of ontology in the persuasiveness of six lines prediction in combination with ostensive detachment suggests a direction for future comparative research concerning the social conditions under which divination systems are more likely to be presented in terms of ontological claims. Calculatory forms of divination prosper in contemporary China. Although I am not 
aware of any systematic analyses of the distribution of divination practices in China, my impression from fieldwork and wider travel in the country is that visible divination practices in cities tend to be calculatory-like six lines, bazi, or fengshui. The intuitive authority of divination is relative, depending on the absence of better alternative sources of information (Boyer 2020); therefore, it is fair to hypothesize that for a divination system to thrive as a practice in contexts in which such sources exist, it needs to be relatively more persuasive than it would be elsewhere. Notably, the authority and persuasiveness of six lines prediction are not sufficient for it to be typically consulted on all matters for which apparently more effective methods of inquiry exist, such as weather forecasting, even if it used to diagnose, for example, health problems. Particularly in modern Chinese cities, where scientific sources of information about the world are lauded and where the Internet and other communication technologies mean that information on almost any subject is readily accessible, we might expect that for divination to survive as a practice it needs to be especially effective at generating ostensive detachment and being reflectively persuasive. The immediate accessibility of information extends to traditional cosmological knowledge, including correlative cosmology, which means that it can be applied to everyday problems (for which science may not be considered relevant) without the need for divinatory consultation. All this suggests that it is not only the persuasiveness afforded by its ontological claims or its ostensive detachment, but the combination of both that allows calculatory divination to remain culturally salient in cities like Hangzhou. Indeed, this is further facilitated by information technology, as manifested in apps and websites which provide calculatory divination services that also include versions of stick divination, explained according to the correlative framework.

To conclude, there is room for future research to explore the relationship between the prevalence of divination systems, on the one hand, and the accessibility of alternative information sources and hegemonic forms of knowledge, on the other. Based on the case of six lines prediction, the following hypotheses may prove fruitful for examination in China and elsewhere:

- Ontological elaboration will be more prevalent in the presence of alternative sources of knowledge that render ostensive detachment insufficient for divination to maintain its persuasiveness, for example, the flourishing of six lines prediction alongside the introduction of technologies that increase the ostensive detachment of other sources of information such as writing.

- In the context of states whose legitimacy depends on a particular cosmology (as in the Han dynasty) and those that have a monopoly on legitimate knowledge, ontologically elaborated divination will be more prevalent if it is based on this cosmology, as it will provide a persuasive source of knowledge. 
- Whether calculatory or agentive elaboration prevails will depend on the content of such cosmologies, for example, divination became calculatory in Han China, but was agentive in ancient Greece and Rome where state legitimacy depended on a cosmology of gods.

- Ontologically elaborated divination will be more common where a particular form of knowledge or ideology is linked to social prestige or political power that may be opposed to divination (as with science in contemporary China).

While speculative, these hypotheses point to some possible avenues of inquiry from the starting point of the role of ontological elaboration in persuasiveness. This requires attention to historical factors, including the creation and spread of cosmologies that logically entail the possibility of divination, or the assimilation of non-ontological techniques into wider belief systems. This would allow examination of further outstanding matters, including the fact that this does not happen to all divination systems, and that ontologically elaborated divination techniques may persist even when the underlying ontological principles cease to have salience in other domains. Further comparative work can help develop a body of cumulative ethnographic and historical data that has the potential to answer such long-standing questions about the transmission and evolution of divinatory practices.

\section{Acknowledgments}

My thanks to my fellow contributors and the participants in the workshop held at LSE in June 2019 from which these ideas developed, as well as to Hans Steinmüller and the two anonymous reviewers for their comments and suggestions. The fieldwork drawn on in this article was funded by the Economic and Social Research Council (grant number ES/J500185/1).

William Matthews is a Fellow in the Anthropology of China at the London School of Economics. He has conducted ethnographic research on Yijing divination in the People's Republic of China and studies the relationship between cognition, the transmission of cosmological ideas, and the politics of knowledge in contemporary and early China. He has published articles on divination in China and the anthropology of ontology and is the author of Cosmic Coherence: A Cognitive Anthropology through Chinese Divination, which will be published by Berghahn Books in 2022. E-mail: w.matthews1@lse.ac.uk 


\section{Notes}

1. While clients generally have little knowledge of the properties of specific trigrams and hexagrams, what they are, both as part of the Yijing's content and as indices of cosmic conditions, is common knowledge and extends into cognate domains.

2. As Holbraad and Pedersen (2017) point out, this is notably distinct from a separate 'ontological turn', with which they themselves identify, focused on reconceptualizing anthropological assumptions in terms of specific ethnographically derived concepts.

3. People also make intuitive ontological assumptions (Baumard and Boyer 2013; Boyer 1998; Matthews 2022) that are not subject to conscious scrutiny except after the fact. These relate to very basic perceptual assumptions-such as an expectation that solid objects collide rather than fuse together-and are not directly relevant to the present discussion.

4. A 'deep ontology' approach might contend that, nonetheless, the act of divination in these cases presupposes a distinct ontology. Consideration of both cognition and ethnography provides no evidence for why this need be the case, other than as an interpretive construct on the part of an anthropologist (Matthews 2022).

5. Throughout I use these terms in the strict senses defined in this section.

6. Divination may be intuitively authoritative but not reflectively persuasive: a skeptic may not believe reflectively that the practice is based on sound epistemological principles, yet still find a verdict uncanny or intrinsically compelling. Likewise, one may be persuaded that divination can work in principle, but decide not to adhere to the authority of a verdict or to find it intuitively convincing. And of course one can either adhere to its authority and be persuaded or be skeptical of the entire enterprise.

7. This is separate from the comparative distinction drawn throughout this special issue between agentive and calculatory forms of divination, which pertains to reflective explanations of divinatory epistemology rather than the role that interpretive procedure grants to intuitive associations.

8. Note, though, that in some forms or contexts other than that described above, additional commentary may be offered, and this may have an effect on stick divination's generative character.

9. As distinct from the 'calculatory' form of explicit reflective ontological and epistemological elaboration (see the introduction to this issue).

10. The cosmology of $q i$ and the Five Phases extends far beyond divination, and such inquiries are resolved through looking at the propensities of individual personalities based on the correlates of time and date of birth, and how the correlates of the inquirer (as an index of their own $q i$ ) will interact with those of others and with different temporal stages and locations.

11. The Yijing's origins predate the first empires by several centuries.

12. Homola (2013) discusses similar policies in Taiwan. 
13. While the latter may be equally persuasive, as they draw on the same ideas, the absence of randomizing mechanisms such as coins may make them less intuitively authoritative.

14. Other forms of divination, such as spirit possession, lend themselves to elaboration in terms of agentive ontology rather than calculatory ontology.

\section{References}

Baumard, Nicolas, and Pascal Boyer. 2013. "Religious Beliefs as Reflective Elaborations on Intuitions: A Modified Dual-Process Model." Current Directions in Psychological Science 22 (4): 295-300. https://doi.org/10.1177/0963721413478610.

Boyer, Pascal. 1998. “Cognitive Tracks of Cultural Inheritance: How Evolved Intuitive Ontology Governs Cultural Transmission.” American Anthropologist 100 (4): 876-889. https://doi.org/10.1525/aa.1998.100.4.876.

Boyer, Pascal. 2010. "Why Evolved Cognition Matters to Understanding Cultural Cognitive Variations.” Interdisciplinary Science Reviews 35 (3-4): 376-386. https://doi.org/10.1179/030801810X12772143410449.

Boyer, Pascal. 2020. "Why Divination? Evolved Psychology and Strategic Interaction in the Production of Truth.” Current Anthropology 61 (1): 100-123. https://doi.org/10.1086/706879.

Chau, Adam Yuet. 2006. Miraculous Response: Doing Popular Religion in Contemporary China. Stanford, CA: Stanford University Press.

Descola, Philippe. 2013. Beyond Nature and Culture. Trans. Janet Lloyd. Chicago: University of Chicago Press.

Elman, Benjamin A. 2005. On Their Own Terms: Science in China, 1550-1900. Cambridge, MA: Harvard University Press.

Evans, Jonathan St. B. T. 2009. "How Many Dual-Process Theories Do We Need? One, Two, or Many?” In Evans and Frankish 2009, 33-54.

Evans, Jonathan St. B. T., and Keith Frankish, eds. 2009. In Two Minds: Dual Processes and Beyond. Oxford: Oxford University Press.

Evans-Pritchard, E. E. (1937) 1976. Witchcraft, Oracles and Magic among the Azande. Abr. Eva Gillies. Oxford: Clarendon Press.

Feuchtwang, Stephan. 1974. An Anthropological Analysis of Chinese Geomancy. Taipei: Southern Materials Center.

Freedman, Maurice. 1979. "Chinese Geomancy: Some Observations in Hong Kong.” In The Study of Chinese Society: Essays, ed. G. William Skinner, 189211. Stanford, CA: Stanford University Press.

Haidt, Jonathan. 2001. “The Emotional Dog and Its Rational Tail: A Social Intuitionist Approach to Moral Judgment.” Psychological Review 108 (4): 814-834. http://dx.doi.org/10.1037/0033-295X.108.4.814.

Hammerstrom, Erik J. 2015. The Science of Chinese Buddhism: Early TwentiethCentury Engagements. New York: Columbia University Press. 
Holbraad, Martin. 2012. Truth in Motion: The Recursive Anthropology of Cuban Divination. Chicago: University of Chicago Press.

Holbraad, Martin, and Morten Axel Pedersen. 2017. The Ontological Turn: An Anthropological Exposition. Cambridge: Cambridge University Press.

Homola, Stéphanie. 2013. "Pursue Good Fortune and Avoid Calamity: The Practice and Status of Divination in Contemporary Taiwan.” Journal of Chinese Religions 41 (2): 124-147. https://doi.org/10.1179/0737769X13Z.0000000005.

Homola, Stéphanie. 2014. "The Fortunes of a Scholar: When the Yijing Challenged Modern Astronomy.” Journal of Asian Studies 73 (3): 733-752. https://www. jstor.org/stable/43553343.

Hulsewé, A. F. P. 1986. “The Two Early Han ‘i cHing’ Specialists Called Ching Fang." T'oung Pao 72 (1): 161-162. https://doi.org/10.1163/156853286X00132. Jung, C. G. 1989. "Foreword.” In The I Ching or Book of Changes, trans. Richard Wilhelm and Cary F. Baynes, xxi-xxxix. London: Penguin.

Lackner, Michael. 2012. “The Last Stand of 'Chinese Science': Yuan Shushan, Traditional Divination and Western Knowledge in Republican China.” Paper presented at the conference "Divinatory Traditions in East Asia: Historical, Comparative and Transnational Perspectives,” Rice University, Houston, TX, February.

Li, Geng. 2019. Fate Calculation Experts: Diviners Seeking Legitimation in Contemporary China. New York: Berghahn Books.

Loewe, Michael. 2005. Faith, Myth, and Reason in Han China. Repr. ed. Indianapolis, IN: Hackett Publishing.

Lynn, Richard John, trans. 1994. The Classic of Changes: A New Translation of the 'I Ching' as Interpreted by Wang Bi. New York: Columbia University Press.

Matthews, William. 2017a. “Making 'Science’ from 'Superstition': Conceptions of Knowledge Legitimacy among Contemporary Yijing Diviners." Journal of Chinese Religions 45 (2): 173-196. https://doi.org/10.1080/07377 69X.2017.1345193.

Matthews, William. 2017b. "Ontology with Chinese Characteristics: Homology as a Mode of Identification." HAU: Journal of Ethnographic Theory 7 (1): 265-285.

Matthews, William. 2018. "Encompassing the Horse: Analogy, Category, and Scale in the Yijing.” British Journal of Chinese Studies 8 (1): 32-61. https://doi. org/10.51661/bjocs.v8i1.19.

Matthews, William. 2022. Cosmic Coherence: A Cognitive Anthropology through Chinese Divination. New York: Berghahn Books.

Matthews, William. Forthcoming a. "Reducing Uncertainty: Six Lines Prediction in Contemporary China.” In The Other Yijing, ed. Tze-Ki Hon. Leiden: Brill.

Matthews, William. Forthcoming b. "Reduction, Generation, and Truth: A Comparative Approach to Divinatory Interpretation.” Current Anthropology.

Parkin, David J. 1991. "Simultaneity and Sequencing in the Oracular Speech of Kenyan Diviners.” In African Divination Systems: Ways of Knowing, ed. Philip M. Peek, 173-189. Bloomington: Indiana University Press.

Scott, Michael W. 2007. The Severed Snake: Matrilineages, Making Place, and a Melanesian Christianity in Southeast Solomon Islands. Durham, NC: Carolina Academic Press. 
Smith, Eliot R., and Elizabeth C. Collins. 2009. "Dual-Process Models: A Social Psychological Perspective.” In Evans and Frankish 2009, 197-216.

Sperber, Dan. 1997. “Intuitive and Reflective Beliefs.” Mind \& Language 12 (1): 67-83. https://doi.org/10.1111/j.1468-0017.1997.tb00062.x.

Sperber, Dan, Fabrice Clément, Christophe Heintz, et al. 2010. "Epistemic Vigilance.” Mind \& Language 25 (4): 359-393. https://doi. org/10.1111/j.1468-0017.2010.01394.x.

Stafford, Charles. 2009. "Numbers and the Natural History of Imagining the Self in Taiwan and China.” Ethnos 74 (1): 110-126. https://doi. org/10.1080/00141840902751238.

Swancutt, Katherine. 2006. "Representational vs Conjectural Divination: Innovating Out of Nothing in Mongolia." Journal of the Royal Anthropological Institute 12 (2): 331-353. https://doi.org/10.1111/j.1467-9655.2006.00294.x.

Tedlock, Barbara. 2001. "Divination as a Way of Knowing: Embodiment, Visualisation, Narrative, and Interpretation.” Folklore 112 (2): 189-197. https://doi. org/10.1080/00155870120082236.

Zeitlyn, David. 1987. “Mambila Divination.” Cambridge Journal of Anthropology 12 (1): 20-51.

Zeitlyn, David. 1990. "Professor Garfinkel Visits the Soothsayers: Ethnomethodology and Mambila Divination.” Man (n.s.) 25 (4): 654-666. https://doi. org/10.2307/2803659.

Zeitlyn, David. 1993. "Spiders in and out of Court or 'the Long Legs of the Law': Styles of Spider Divination in Their Sociological Contexts.” Africa 63 (2): 219240. https://doi.org/10.2307/1160842. 